\title{
Modelo de promoción de la salud para asegurar el buen desarrollo escolar en instituciones educativas del distrito de la banda de Shilcayo, 2021
}

\author{
Danny Armas Murrieta \\ aarmasmu@ucvvirtual.edu.pe \\ Dr. Keller Sánchez Dávila \\ ksanchezd@ucv.edu.pe \\ Universidad Cesar Vallejo
}

\section{RESUMEN}

La investigación se planteó con el fin de diseñar una propuesta de un modelo de promoción de la salud que contribuya al desarrollo escolar en Instituciones educativas del distrito de la Banda de Shilcayo, 2021. La investigación fue básica, y pertenece al diseño descriptivo propositivo, donde el estudio deseaba proponer un modelo de promoción de la salud para el desarrollo escolar. Entre los resultados, el estudio distingue cinco paradojas que muestran el mantenimiento de una metodología biomédica y paternalista en la idea y enfoque del bienestar. La OMS reconoce la importancia de los recursos sociales como un agente valioso para cambiar el comportamiento sobre el bienestar y la salud. Las normas sociales pueden influir en gran medida en las elecciones y los comportamientos relacionados con la salud de las personas. El concepto de alfabetización en salud ha sido útil para sostener este cambio. El diseño de los objetivos escolares termina siendo una parte significativa del entorno escolar, generosamente identificado con diferentes elementos del entorno escolar como la naturaleza de la iniciativa y las conexiones entre los instructores. Las estrategias centrales de la gestión del conocimiento de personalización y codificación pueden adoptarse para mejorar el desarrollo escolar. Concluyendo la promoción de la salud es una interacción mundial que permite a las personas expandir la autoridad sobre su bienestar para desarrollarlo aún más, enfocándose en el fortalecimiento de las personas, pero además que considera los círculos políticos, sociales, monetarios y naturales que impactan el bienestar y la salud.

Palabras clave: promoción de la salud; desarrollo escolar; bienestar; salud, normas sociales. 


\title{
Health promotion model to ensure good school development in educational institutions of the Shilcayo band district, 2021
}

\begin{abstract}
The research was proposed in order to design a proposal for a health promotion model that contributes to school development in educational institutions of the Banda de Shilcayo district, 2021. The research was basic, and belongs to the descriptive purposeful design, where the study wanted to propose a health promotion model for school development. Among the results, the study distinguishes five paradoxes that showed the maintenance of a biomedical and paternalistic methodology in the idea and approach of well-being. WHO recognizes the importance of social resources as a valuable agent to change behavior on well-being and health. Social norms can greatly influence people's choices and health-related behaviors. The concept of health literacy has been helpful in sustaining this change. The design of school goals ends up being a significant part of the school environment, generously identified with different elements of the school environment such as the nature of the initiative and the connections between instructors. The core knowledge management strategies of personalization and coding can be adopted to improve school development. Concluding health promotion is a global interaction that allows people to expand authority over their well-being to further develop it, focusing on the empowerment of people, but also that considers the political, social, monetary and natural circles that impact the wellness and health.
\end{abstract}

Keywords: health promotion; school development; well-being; health; social norms.

Artículo recibido: 28. Julio. 2021

Aceptado para publicación: 21. Agosto. 2021

Correspondencia: aarmasmu@ucvvirtual.edu.pe

Conflictos de Interés: Ninguna que declarar 


\section{INTRODUCCIÓN}

La salud es un derecho central y un activo en el día a día vital y biopsicosocial de la persona. En consecuencia, se debe desarrollar los hábitos de salud en la población desde pequeños (Cajina, 2020). La promoción de la salud es s una interacción política y social mundial que incorpora no solo actividades que apuntan directamente a fortalecer las capacidades y límites de las personas, sino también aquellas que apuntan a alterar las condiciones sociales, ecológicas y monetarias, para moderar su efecto sobre el bienestar abierto e individual (Organización Mundial de la Salud [OMS], 2016). Asimismo, dinamiza cambios en el clima que contribuye en el avance y la salud, Además, se basa en la población, es participativa, intersectorial y en un entorno delicado (Organización Panamericana de la Salud [OPS], 2020). Sin embargo, es importante destacar que la promoción de la salud va más allá de la evitación o incluso de la instrucción del bienestar. Se une a factores sociales que tienen que ver con el bienestar. Bienestar que se percibe en su idea amplia, como un objetivo en sí mismo, pero como un activo para el día a día, para la satisfacción personal y la prosperidad (Sarria y Del Villar, 2014, p.56).

A nivel educativo, implica plantear deliberadamente puertas abiertas de aprendizaje orientadas a desarrollar aún más la competencia del bienestar, que incorpora trabajar con la información sobre la población y crear habilidades individuales que conducen a un mejor bienestar. Su objetivo es sumarse a la promoción humana básica de los estudiantes suplentes y del ámbito instructivo local a través del fortalecimiento de las actividades de promoción del bienestar en los Centros Educativos. A partir de ello, el Ministerio de Salud del Perú ha creado técnicas de avance del bienestar orientadas a trabajar en el bienestar y satisfacción personal de las masas populares, avanzar en cambios de prácticas y perspectivas, desarrollando aún más el ingreso a las administraciones de salud (MINSA, 2017). Estrategias, situadas de modo que la población estudiantil y el local instructivo acepten que el bienestar es cualquier cosa menos una asignación sanitaria, sino un proyecto social, vinculada a deberes individuales y políticos (Reátegui, 2008).

Actualmente, los gobiernos tomaron medidas vitales para el avance ininterrumpido de la capacitación debido a la increíble emergencia de bienestar debido a COVID 19. En particular, enfocándose en tres columnas fundamentales, el envío de modalidades de aprendizaje a distancia, utilizando una variedad de arreglos y etapas (con o sin utilización de la innovación); respaldo y activación de personal y redes de instrucción, y cuidado del 
bienestar y la prosperidad total de los estudiantes (Organización de las Naciones Unidas para la Educación, la Ciencia y la Cultura [UNESCO], 2020).

Mediante el desarrollo y la utilización de dispositivos instructivos en configuración virtual, se avanzó en la base de diversos espacios de apoyo a la formación y al avance del bienestar para una mejor atención médica. La educación es y ha tenido un punto clave con respecto a la evitación y el avance del bienestar. Los niños, jóvenes y adolescentes son los mejores socios para sacar a la luz los problemas en la arena pública en lo que respecta a las acciones que deben tomarse para prevenir, y las actividades y opciones que permiten avanzar en el bienestar en la vida cotidiana. Es por ello que los planes curriculares que sitúan a diversos grados de aprendizaje tienen como tema informativo o transversal un pivote denominado "Bienestar y Calidad de Vida", a partir de ese punto y desde la crisis que se está atravesando se busca que el Los docentes de las escuelas realizan recomendaciones que hacen hincapié en la evitación y el avance del bienestar del Covid-19 (Arias Ortiz et al., 2020).

Esto la verdad se refleja adicionalmente en Perú, con el espacio de estudio en el área de La Banda de Shilcayo - Provincia de San Martín, donde es importante destacar que los programas de promoción de la salud, también muestran información sobre higiene, nutrición, prevención de contratiempos, saneamiento y diferentes temas, en los que se destaca la conciencia de las medidas de lavado de manos, por ejemplo, la utilización de licor gel, la limpieza en el cuidado de los alimentos y la dispersión de estos en Instituciones Educativas ya sea de manera esencial o presencial, siguiendo convenciones de bioseguridad.

En cualquier caso, la mayoría de los programas de promoción de la salud tienen un procedimiento instruccional acostumbrado que descuida comunicar de manera efectiva la información que impulsa el fomento de las habilidades importantes para recibir mejores formas de vida, particularmente en la circunstancia en la que vivimos. Hay factores que limitan la consideración de este material en los programas educativos instructivos, a la luz del daño a la solidez de los estudiantes que pueden influir directamente en su aprendizaje; y estos componentes son la ausencia de responsabilidad política, materiales, coordinaciones, ayuda especializada y coordinación entre el Bienestar Regional la Junta de la Municipalidad Provincial de San Martín, la Dirección Regional de Salud de San Martín (DIRES) y Educación. 


\section{MATERIAL Y MÉTODOS}

\section{Diseño de estudio}

Es tipo básica, la cual se caracteriza por la descripción de los hechos y fenómenos en su estado natural (Hernández et al., 2014).

Pertenece al diseño descriptivo propositivo. Este diseño se caracteriza por tener el siguiente esquema:

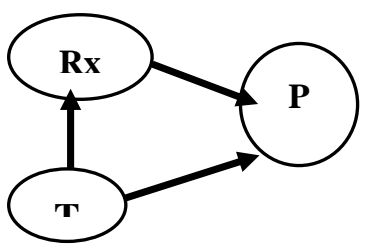

\section{Dónde:}

Rx : Diagnóstico de la realidad de la promoción de la salud escolar en las I.E. del distrito de la Banda de Shilcayo, 2021.

T : Estudios teóricos.

P : Propuesta validada

\section{Procedimiento de recolección de datos}

Según la finalidad del estudio de proponer un modelo de promoción de la salud para el desarrollo escolar, se solicitó permiso a las autoridades de las instituciones educativas del distrito de la Banda de Shilcayo. Mediante la autorización y el consentimiento de su participación se procedieron a aplicar una encuesta con la finalidad de recolectar la información brindada por los participantes.

\section{Técnicas de análisis de datos}

Después de la recolección de los datos brindada por los participantes, estas fueron digitalizadas para ser procesadas mediante software estadístico. Mediante la estadística descriptiva analizaremos la situación actual del desarrollo escolar y en base a ello se propondrá un modelo de promoción de la salud, la cual será validada por expertos sobre promoción de la salud y desarrollo escolar.

\section{RESULTADOS.}




\subsection{Estudios sobre promoción de la salud}

\begin{tabular}{|c|c|c|c|c|c|}
\hline \multicolumn{6}{|c|}{ DATOS } \\
\hline 1. Autor & Año & \multicolumn{2}{|c|}{ Nombre } & Revista & Vol. y núm. \\
\hline $\begin{array}{l}\text { López, Olga } \\
\text { Canga, Navidad } \\
\text { Mujika, Agurtzane } \\
\text { Pardavila, Miren } \\
\text { Belintxon, Maider } \\
\text { Serrano, Inmaculada } \\
\text { Pumar, María }\end{array}$ & 2017 & \multicolumn{2}{|c|}{$\begin{array}{l}\text { Cinco paradojas de la } \\
\text { promoción de la } \\
\text { salud }\end{array}$} & $\begin{array}{c}\text { Gaceta sanitaria. } \\
\text { https://doi.org/10.1016/j.gaceta.2016.10.011 }\end{array}$ & $31(3)$ \\
\hline \multicolumn{6}{|c|}{ CONTENIDO } \\
\hline Tipo y Diseño & $\begin{array}{c}\text { Población y } \\
\text { Muestra }\end{array}$ & Instrumentos & $\begin{array}{l}\text { Aspectos } \\
\text { éticos }\end{array}$ & Resultados & Conclusión \\
\hline $\begin{array}{c}\text { Tipo básica } \\
\text { Diseño no experimental }\end{array}$ & $\begin{array}{c}9 \\
\text { conferencias } \\
\text { mundiales } \\
\text { sobre } \\
\text { promoción de } \\
\text { la salud }\end{array}$ & $\begin{array}{c}\text { Guía de } \\
\text { análisis } \\
\text { documentario }\end{array}$ & $\begin{array}{l}\text { Presentación } \\
\text { de } \\
\text { información } \\
\text { objetiva }\end{array}$ & $\begin{array}{l}\text { El estudio distingue cinco paradojas que } \\
\text { muestran el mantenimiento de una metodología } \\
\text { biomédica y paternalista en la idea y enfoque del } \\
\text { bienestar. El avance del bienestar requiere, no } \\
\text { obstante, diferentes tipos de modelos que } \\
\text { permitan estrechar el hueco entre la forma de } \\
\text { hablar y la práctica. }\end{array}$ & $\begin{array}{l}\text { Asistir e identificar líneas de actuación } \\
\text { diferenciadoras en el avance del } \\
\text { bienestar que hagan concebible una } \\
\text { formación más de cerca a las } \\
\text { hipotéticas señales que se han } \\
\text { planteado hasta este punto. Esto se } \\
\text { sumaría a trabajar en el bienestar } \\
\text { individual y social, garantizando la } \\
\text { sustentabilidad tanto del bienestar } \\
\text { como del marco financiero en general. }\end{array}$ \\
\hline
\end{tabular}

Ciencia Latina Revista Científica Multidisciplinar, Ciudad de México, México.

ISN 2707-2207 / ISSN 2707-2215 (en línea), setiembre-octubre, 2021, Volumen 5, Número 5. https://doi.org/10.37811/cl_rcm.v5i5.792 p.6733 


\begin{tabular}{|c|c|c|c|c|c|}
\hline \multicolumn{6}{|c|}{ DATOS } \\
\hline 2. Autor & Año & \multicolumn{2}{|c|}{ Nombre } & Revista & Vol. y núm. \\
\hline $\begin{array}{l}\text { O'Connor, Clare } \\
\text { Dyson, Judith } \\
\text { Cowdell, Fiona } \\
\text { Watson, Roger }\end{array}$ & (2018) & \multicolumn{2}{|c|}{$\begin{array}{c}5 \text { Do universal school-based mental } \\
\text { health promotion programmes } \\
\text { improve the mental health and } \\
\text { emotional wellbeing of young people? } \\
\text { A literature review }\end{array}$} & $\begin{array}{c}\text { Journal of Clinical Nursing } \\
\text { https://doi.org/10.1111/jocn.14078 }\end{array}$ & 27 (34) \\
\hline \multicolumn{6}{|c|}{ CONTENIDO } \\
\hline Tipo y Diseño & $\begin{array}{l}\text { Población } \\
\text { y Muestra }\end{array}$ & Instrumentos & Aspectos éticos & Resultados & Conclusión \\
\hline $\begin{array}{l}\text { Tipo básica } \\
\text { Diseño no } \\
\text { experimental }\end{array}$ & 29 estudios & $\begin{array}{l}\text { Guía de análisis } \\
\text { documentario }\end{array}$ & $\begin{array}{l}\text { Presentación de } \\
\text { información objetiva }\end{array}$ & $\begin{array}{l}\text { El análisis temático generó tres temas claves: (i) } \\
\text { búsqueda de ayuda y afrontamiento; (ii) bienestar } \\
\text { social y emocional; y } \quad \text { (iii) efectividad } \\
\text { psicoeducativa. }\end{array}$ & $\begin{array}{l}\text { Los estudios muestran } \\
\text { resultados prometedores, es } \\
\text { necesario realizar más } \\
\text { estudios de evaluación } \\
\text { sólidos para guiar la práctica } \\
\text { futura. }\end{array}$ \\
\hline
\end{tabular}

Ciencia Latina Revista Científica Multidisciplinar, Ciudad de México, México.

ISN 2707-2207 / ISSN 2707-2215 (en línea), setiembre-octubre, 2021, Volumen 5, Número 5. https://doi.org/10.37811/cl_rcm.v5i5.792 p.6734 


\begin{tabular}{|c|c|c|c|c|c|}
\hline \multicolumn{6}{|c|}{ DATOS } \\
\hline 3. Autor & Año & Non & bre & Revista & Vol. y núm. \\
\hline $\begin{array}{l}\text { Jane, Monica } \\
\text { Hagger, Martin } \\
\text { Foster, Jonathan } \\
\text { Ho, Suleen } \\
\text { Pal, Sebely }\end{array}$ & (2018) & \multicolumn{2}{|c|}{$\begin{array}{l}\text { Social media for health } \\
\text { promotion and weight } \\
\text { management: a critical } \\
\text { debate }\end{array}$} & $\begin{array}{c}\text { BMC Public Health } \\
\text { https://doi.org/10.1186/s12889-018-5837-3 }\end{array}$ & $18(1)$ \\
\hline \multicolumn{6}{|c|}{ CONTENIDO } \\
\hline $\begin{array}{l}\text { Tipo y Diseño de } \\
\text { Investigación }\end{array}$ & $\begin{array}{l}\text { Población } \\
\text { y } \\
\text { Muestra }\end{array}$ & Instrumentos & $\begin{array}{l}\text { Aspectos } \\
\text { éticos }\end{array}$ & Resultados & Conclusión \\
\hline $\begin{array}{l}\text { Tipo básica } \\
\text { Diseño no } \\
\text { experimental }\end{array}$ & $\begin{array}{c}299 \\
\text { usuarios }\end{array}$ & $\begin{array}{l}\text { Guía de análisis } \\
\text { documentario }\end{array}$ & $\begin{array}{l}\text { Presentación } \\
\text { de información } \\
\text { objetiva }\end{array}$ & $\begin{array}{l}\text { La OMS reconoce la importancia de los recursos } \\
\text { sociales como un agente valioso para cambiar el } \\
\text { comportamiento sobre el bienestar y la salud. Los } \\
\text { recursos sociales se traducen a nivel comunitario como } \\
\text { apoyo brindado por otras personas significativas, como } \\
\text { familiares, parejas y compañeros, en forma de } \\
\text { información, ayuda material y estímulo. }\end{array}$ & $\begin{array}{l}\text { El uso de social media en } \\
\text { promocionar la salud es un campo } \\
\text { de investigación emergente, la } \\
\text { investigación preliminar sugiere } \\
\text { que aumenta la participación de los } \\
\text { participantes y puede proporcionar } \\
\text { una herramienta rentable para } \\
\text { brindar apoyo social a las personas } \\
\text { que participan en programas de } \\
\text { control de peso. }\end{array}$ \\
\hline
\end{tabular}

Ciencia Latina Revista Científica Multidisciplinar, Ciudad de México, México.

ISN 2707-2207 / ISSN 2707-2215 (en línea), setiembre-octubre, 2021, Volumen 5, Número 5. https://doi.org/10.37811/cl_rcm.v5i5.792 p.6735 


\begin{tabular}{|c|c|c|c|c|c|}
\hline \multicolumn{6}{|c|}{ DATOS } \\
\hline 4. Autor & Año & & Nombre & Revista & Vol. y núm. \\
\hline $\begin{array}{l}\text { Cislaghi, } \\
\text { Beniamino } \\
\text { Heise, Lori }\end{array}$ & (2019) & \multicolumn{2}{|c|}{$\begin{array}{l}\text { Using social norms theory for health } \\
\text { promotion in low-income countries }\end{array}$} & $\begin{array}{c}\text { Health Promotion International } \\
\text { https://doi.org/10.1093/heapro/day017 }\end{array}$ & $34(3)$ \\
\hline \multicolumn{6}{|c|}{ CONTENIDO } \\
\hline Tipo y Diseño & $\begin{array}{l}\text { Población } \\
\text { y Muestra }\end{array}$ & Instrumentos & Aspectos éticos & Resultados & Conclusión \\
\hline $\begin{array}{l}\text { Tipo básica } \\
\text { Diseño no } \\
\text { experimental }\end{array}$ & 71 estudios & $\begin{array}{l}\text { Guía de análisis } \\
\text { documentario }\end{array}$ & $\begin{array}{c}\text { Presentación de información } \\
\text { objetiva }\end{array}$ & $\begin{array}{l}\text { Las normas sociales pueden influir en } \\
\text { gran medida en las elecciones y los } \\
\text { comportamientos relacionados con la } \\
\text { salud de las personas. }\end{array}$ & $\begin{array}{l}\text { Las intervenciones de normas sociales } \\
\text { en los países de ingresos bajos y } \\
\text { medianos carecen de un marco para } \\
\text { comprender cómo las normas } \\
\text { interactúan con otros factores que } \\
\text { sustentan las prácticas y } \\
\text { comportamientos nocivos. Esta } \\
\text { brecha ha llevado a intervenciones } \\
\text { miopes que se enfocan } \\
\text { exclusivamente en las normas sociales } \\
\text { sin una conciencia más amplia de } \\
\text { cómo otros factores institucionales, } \\
\text { materiales, individuales y sociales } \\
\text { afectan la práctica nociva. }\end{array}$ \\
\hline
\end{tabular}




\section{DATOS}

\begin{tabular}{|c|c|c|c|c|c|}
\hline 5. Autor & Año & \multicolumn{2}{|c|}{ Nombre } & Revista & Vol. y núm. \\
\hline $\begin{array}{l}\text { Albahri, A } \\
\text { Alwan, Jwan } \\
\text { Taha, Zahraa } \\
\text { Ismail, Sura } \\
\text { Hamid, Rula } \\
\text { Zaidan, A } \\
\text { Albahri, O } \\
\text { Zaidan, B } \\
\text { Alamoodi, A } \\
\text { Alsalem, M }\end{array}$ & 2021 & \multicolumn{2}{|c|}{$\begin{array}{l}\text { IoT-based telemedicine } \\
\text { for disease prevention } \\
\text { and health promotion: } \\
\text { State-of-the-Art }\end{array}$} & $\begin{array}{l}\text { Journal of Network and Computer Applications } \\
\underline{\text { https://doi.org/10.1016/j.jnca.2020.102873 }}\end{array}$ & $173(1)$ \\
\hline \multicolumn{6}{|c|}{ CONTENIDO } \\
\hline Tipo y Diseño & $\begin{array}{c}\text { Población y } \\
\text { Muestra }\end{array}$ & Instrumentos & $\begin{array}{l}\text { Aspectos } \\
\text { éticos }\end{array}$ & Resultados & Conclusión \\
\hline $\begin{array}{l}\text { Tipo básica } \\
\text { Diseño no } \\
\text { experimental }\end{array}$ & $\begin{array}{c}141 \\
\text { artículos } \\
\text { desde } 2014 \\
\text { hasta julio } \\
\text { de } 2020\end{array}$ & $\begin{array}{c}\text { Guía de análisis } \\
\text { documentario }\end{array}$ & $\begin{array}{l}\text { Presentación } \\
\text { de información } \\
\text { objetiva }\end{array}$ & $\begin{array}{l}\text { Varias aplicaciones de telemedicina que cubren } \\
\text { diversas enfermedades humanas han presentado sus } \\
\text { trabajos desde una perspectiva específica y han } \\
\text { generado confusión con respecto a las características } \\
\text { del internet de las coas. }\end{array}$ & $\begin{array}{l}\text { Los seres humanos necesitan esfuerzos } \\
\text { de telemedicina eficientes, que puedan } \\
\text { satisfacer la demanda de poblaciones } \\
\text { mayores y mayores a un costo } \\
\text { asequible. Al presentar los resultados, } \\
\text { los investigadores de todo el mundo han } \\
\text { comenzado a examinar soluciones para } \\
\text { la práctica médica de una manera que } \\
\text { reforma los servicios de telemedicina al } \\
\text { centrarse en el potencial de la internet } \\
\text { de las coas. }\end{array}$ \\
\hline
\end{tabular}

Ciencia Latina Revista Científica Multidisciplinar, Ciudad de México, México.

ISN 2707-2207 / ISSN 2707-2215 (en línea), setiembre-octubre, 2021, Volumen 5, Número 5. https://doi.org/10.37811/cl rcm.v5i5.792 p.6737 


\begin{tabular}{|c|c|c|c|c|c|}
\hline \multicolumn{6}{|c|}{ DATOS } \\
\hline 6. Autor & Año & \multicolumn{2}{|c|}{ Nombre } & Revista & Vol. y núm. \\
\hline Nutbeam, Don & (2019) & \multicolumn{2}{|c|}{$\begin{array}{l}\text { Health education and } \\
\text { health promotion } \\
\text { revisited }\end{array}$} & $\begin{array}{c}\text { Health Education Journal } \\
\underline{\text { https://doi.org/10.1177\%2F0017896918770215 }}\end{array}$ & $78(6)$ \\
\hline \multicolumn{6}{|c|}{ CONTENIDO } \\
\hline Tipo y Diseño & $\begin{array}{l}\text { Población } \\
\text { y Muestra }\end{array}$ & Instrumentos & $\begin{array}{l}\text { Aspectos } \\
\text { éticos }\end{array}$ & Resultados & Conclusión \\
\hline $\begin{array}{l}\text { Tipo básica } \\
\text { Diseño no } \\
\text { experimental }\end{array}$ & $\begin{array}{c}13 \\
\text { artículos }\end{array}$ & $\begin{array}{c}\text { Guía de } \\
\text { análisis } \\
\text { documentario }\end{array}$ & $\begin{array}{l}\text { Presentación } \\
\text { de } \\
\text { información } \\
\text { objetiva }\end{array}$ & $\begin{array}{l}\text { El concepto de alfabetización en salud ha sido útil para sostener } \\
\text { este cambio. A medida que las herramientas de comunicación han } \\
\text { sido transformadas por la comunicación digital y el mercado de } \\
\text { la comunicación se ha vuelto más concurrido y complejo, la } \\
\text { educación para la salud ha seguido evolucionando para reflejar } \\
\text { estos cambios }\end{array}$ & $\begin{array}{l}\text { Permite que las personas } \\
\text { naveguen por fuentes de } \\
\text { información en competencia y se } \\
\text { involucren de manera } \\
\text { significativa con } \\
\text { determinantes sociales } \\
\text { económicos de la salud. El acceso } \\
\text { equitativo a la educación sanitaria } \\
\text { de calidad y el aprendizaje } \\
\text { permanente siguen siendo las } \\
\text { piedras angulares de la } \\
\text { promoción moderna de la salud }\end{array}$ \\
\hline
\end{tabular}

Ciencia Latina Revista Científica Multidisciplinar, Ciudad de México, México.

ISN 2707-2207 / ISSN 2707-2215 (en línea), setiembre-octubre, 2021, Volumen 5, Número 5. https://doi.org/10.37811/cl_rcm.v5i5.792 p.6738 


\begin{tabular}{|c|c|c|c|c|c|}
\hline \multicolumn{6}{|c|}{ DATOS } \\
\hline 7. Autor & Año & & Nombre & Revista & Vol. y núm. \\
\hline Laverack, Glenn & (2017) & 10 The Cha & $\begin{array}{l}\text { ge of Behaviour Change and } \\
\text { Health Promotion }\end{array}$ & $\begin{array}{c}\text { Challenges } \\
\text { https://doi.org/10.3390/challe8020025 }\end{array}$ & $8(2)$ \\
\hline \multicolumn{6}{|c|}{ CONTENIDO } \\
\hline Tipo y Diseño & $\begin{array}{l}\text { Población y } \\
\text { Muestra }\end{array}$ & Instrumentos & Aspectos éticos & Resultados & Conclusión \\
\hline $\begin{array}{l}\text { Tipo básica } \\
\text { Diseño no } \\
\text { experimental }\end{array}$ & 15 artículos & $\begin{array}{c}\text { Guía de } \\
\text { análisis } \\
\text { documentario }\end{array}$ & $\begin{array}{c}\text { Presentación de información } \\
\text { objetiva }\end{array}$ & $\begin{array}{l}\text { La evidencia sobre la efectividad de } \\
\text { los enfoques de cambio de } \\
\text { comportamiento qué funciona y qué } \\
\text { no funciona no está clara. Lo que sí } \\
\text { sabemos es que las intervenciones } \\
\text { individuales que se dirigen a un riesgo } \\
\text { conductual específico tienen poco } \\
\text { impacto en los determinantes que } \\
\text { realmente causan mala salud, } \\
\text { especialmente para las personas } \\
\text { vulnerables. }\end{array}$ & $\begin{array}{l}\text { El futuro del cambio de } \\
\text { comportamiento y la promoción } \\
\text { de la salud pasa por la aplicación } \\
\text { de una estrategia integral con } \\
\text { tres componentes centrales: (1) } \\
\text { un enfoque de cambio de } \\
\text { comportamiento; (2) un marco } \\
\text { de políticas sólido que crea un } \\
\text { entorno de apoyo y (3) e } \\
\text { empoderamiento de las personas } \\
\text { para obtener más control sobre la } \\
\text { toma de decisiones sobre estilos } \\
\text { de vida saludables }\end{array}$ \\
\hline
\end{tabular}




\section{DATOS}

\begin{tabular}{|c|c|c|c|c|c|}
\hline 8. Autor & Año & \multicolumn{2}{|c|}{ Nombre } & Revista & Vol. y núm. \\
\hline $\begin{array}{l}\text { Verra, Sanne } \\
\text { Benzerga, Amel } \\
\text { Jiao, Boshen } \\
\text { Ruggeri, Kai }\end{array}$ & (2019) & \multicolumn{2}{|c|}{$\begin{array}{l}11 \text { Health Promotion at Work: } \\
\text { A Comparison of Policy and } \\
\text { Practice Across Europe }\end{array}$} & $\begin{array}{c}\text { Safety and Health at Work } \\
\underline{\text { https://doi.org/10.1016/j.shaw.2018.07.003 }}\end{array}$ & $10(1)$ \\
\hline \multicolumn{6}{|c|}{ CONTENIDO } \\
\hline Tipo y Diseño & $\begin{array}{l}\text { Población } \\
\text { y Muestra }\end{array}$ & Instrumentos & Aspectos éticos & Resultados & Conclusión \\
\hline $\begin{array}{l}\text { Tipo básica } \\
\text { Diseño no } \\
\text { experimental }\end{array}$ & 23 artículos & $\begin{array}{l}\text { Guía de análisis } \\
\text { documentario }\end{array}$ & $\begin{array}{l}\text { Presentación de } \\
\text { información } \\
\text { objetiva }\end{array}$ & $\begin{array}{l}\text { Ante la duda, el } 73,1 \% \text { de los establecimientos de } \\
\text { la Unión Europea toman medidas preventivas } \\
\text { frente a daños directos genuinos y alrededor del } \\
35,4 \% \text { toman medidas para evitar aperturas } \\
\text { psicosociales. Solo el } 29,5 \% \text { tiene medidas para } \\
\text { promover la prosperidad. Se percibieron } \\
\text { asociaciones delicadas y conflictivas entre la } \\
\text { metodología de SSO y los indicadores de } \\
\text { capacitación. }\end{array}$ & $\begin{array}{l}\text { Las políticas de salud y seguridad } \\
\text { relacionados con la se centran claramente } \\
\text { en la lucha contra la enfermedad, } \\
\text { mientras que la coherencia con los } \\
\text { ensayos de bienestar y bienestar es } \\
\text { moderadamente baja. Los riesgos } \\
\text { psicosociales se atienden con frecuencia } \\
\text { en los arreglos públicos, sin embargo, no } \\
\text { son llevados a cabo por fundaciones. Las } \\
\text { técnicas actuales de evaluación de } \\
\text { peligros son obsoletas y necesitan } \\
\text { marcadores psicosociales con } \\
\text { regularidad. }\end{array}$ \\
\hline
\end{tabular}

Ciencia Latina Revista Científica Multidisciplinar, Ciudad de México, México.

ISN 2707-2207 / ISSN 2707-2215 (en línea), setiembre-octubre, 2021, Volumen 5, Número 5. https://doi.org/10.37811/cl rcm.v5i5.792 p.6740 
3.2. Estudios revisados sobre desarrollo escolar

\begin{tabular}{|c|c|c|c|c|c|}
\hline \multicolumn{6}{|c|}{ DATOS } \\
\hline 9. Autor & Año & \multicolumn{2}{|c|}{ Nombre } & Revista & Vol. y núm. \\
\hline $\begin{array}{l}\text { Arhipova, Olga } \\
\text { Kokina, Irēna } \\
\text { Michaelsson, Alona }\end{array}$ & (2021) & \multicolumn{2}{|c|}{ 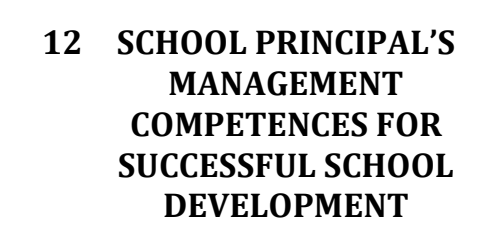 } & $\begin{array}{c}\text { Tiltai } \\
\text { https://e-journals.ku.lt/doi/10.15181/tbb.v78i1.1757 }\end{array}$ & $79(1)$ \\
\hline \multicolumn{6}{|c|}{ CONTENIDO } \\
\hline Tipo y Diseño & $\begin{array}{l}\text { Población } \\
\text { y } \\
\text { Muestra }\end{array}$ & Instrumentos & $\begin{array}{l}\text { Aspectos } \\
\text { éticos }\end{array}$ & Resultados & Conclusión \\
\hline $\begin{array}{l}\text { Tipo básica } \\
\text { Diseño no } \\
\text { experimental }\end{array}$ & $\begin{array}{c}19 \\
\text { artículos }\end{array}$ & $\begin{array}{c}\text { Guía de análisis } \\
\text { documentario }\end{array}$ & $\begin{array}{l}\text { Presentación de } \\
\text { información } \\
\text { objetiva }\end{array}$ & $\begin{array}{l}\text { La solución de los problemas de gestión de la educación en } \\
\text { la región del Báltico se ve muy afectada por las ideas del } \\
\text { enfoque del sistema que tratan las acciones como un sistema } \\
\text { unificado que consta de elementos mutuamente relacionados } \\
\text { con la interacción constante de factores ambientales internos } \\
\text { y externo }\end{array}$ & $\begin{array}{l}\text { Los líderes educativos deben } \\
\text { reconocer y asumir una } \\
\text { responsabilidad compartida } \\
\text { no solo por el desarrollo } \\
\text { intelectual y educativo de los } \\
\text { estudiantes, sino también por } \\
\text { su desarrollo personal, } \\
\text { social, emocional y físico. }\end{array}$ \\
\hline
\end{tabular}

Ciencia Latina Revista Científica Multidisciplinar, Ciudad de México, México.

ISN 2707-2207 / ISSN 2707-2215 (en línea), setiembre-octubre, 2021, Volumen 5, Número 5. https://doi.org/10.37811/cl_rcm.v5i5.792 p.6741 


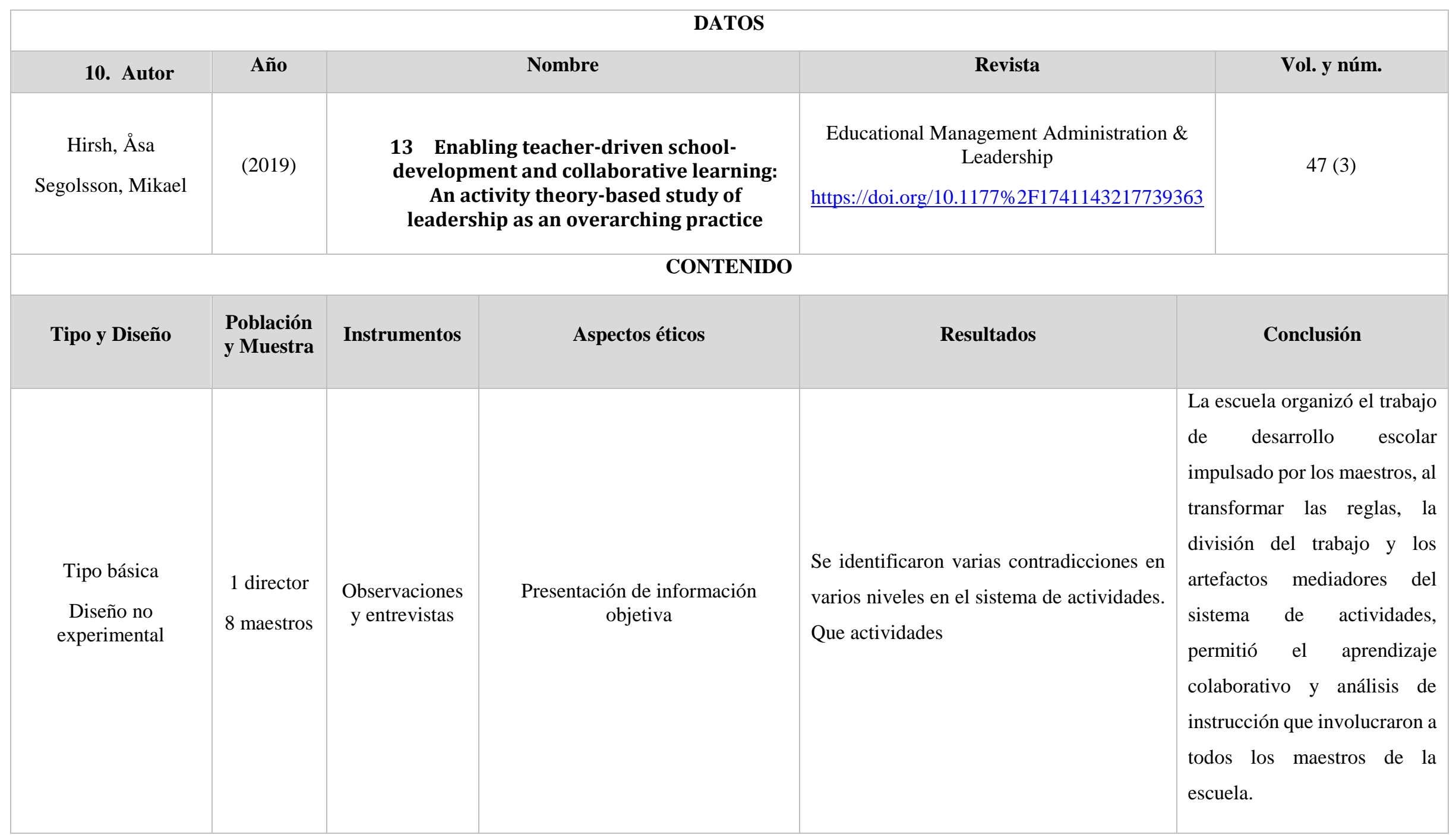




\begin{tabular}{|c|c|c|c|c|c|}
\hline \multicolumn{6}{|c|}{ DATOS } \\
\hline 11. Autor & Año & & Nombre & Revista & Vol. y núm. \\
\hline $\begin{array}{l}\text { Snoek, Marco } \\
\text { Bekebrede, Judith } \\
\text { Hanna, Fadie } \\
\text { Creton, Theun } \\
\text { Edzes, Hester }\end{array}$ & (2017) & $\begin{array}{l}14 \text { The cont } \\
\text { school dev }\end{array}$ & $\begin{array}{l}\text { bution of graduation research to } \\
\text { lopment: graduation research as a } \\
\text { boundary practice }\end{array}$ & $\begin{array}{c}\begin{array}{c}\text { European Journal of Teacher } \\
\text { Education }\end{array} \\
\frac{\text { https://doi.org/10.1080/02619768.201 }}{\underline{7.1315400}}\end{array}$ & $40(3)$ \\
\hline \multicolumn{6}{|c|}{ CONTENIDO } \\
\hline Tipo y Diseño & $\begin{array}{l}\text { Población y } \\
\text { Muestra }\end{array}$ & Instrumentos & Aspectos éticos & Resultados & Conclusión \\
\hline $\begin{array}{l}\text { Tipo básica de caso } \\
\text { múltiple } \\
\text { Diseño no } \\
\text { experimental }\end{array}$ & $\begin{array}{l}30 \text { maestros } \\
y \\
\text { estudiantes }\end{array}$ & $\begin{array}{l}\text { Observaciones y } \\
\text { entrevistas }\end{array}$ & Presentación de información objetiva & $\begin{array}{l}\text { Se adaptó el proyecto de investigación } \\
\text { de graduación dentro de un programa } \\
\text { de formación de maestros de primaria, } \\
\text { tratando de unir el nivel personal donde } \\
\text { los estudiantes-maestros muestran su } \\
\text { competencia individual) y el nivel } \\
\text { colaborativo. }\end{array}$ & $\begin{array}{l}\text { la enseñanza se considera } \\
\text { una actividad colaborativa, } \\
\text { en ese sentido, el objetivo de } \\
\text { los proyectos de } \\
\text { investigación en las escuelas } \\
\text { debe superar los niveles } \\
\text { individuales y personales y } \\
\text { tener como objetivo } \\
\text { contribuir a la reflexión } \\
\text { informada por la } \\
\text { investigación de un equipo } \\
\text { de profesores. }\end{array}$ \\
\hline
\end{tabular}




\section{DATOS}

\begin{tabular}{|c|c|c|c|c|c|}
\hline 12. Autor & Año & \multicolumn{2}{|c|}{ Nombre } & Revista & Vol. y núm. \\
\hline $\begin{array}{l}\text { Mogren, Anna } \\
\text { Gericke, Niklas } \\
\text { Scherp, Hans }\end{array}$ & (2019) & \multicolumn{2}{|c|}{$\begin{array}{c}15 \text { Whole school approaches } \\
\text { to education for } \\
\text { sustainable development: } \\
\text { a model that links to school } \\
\text { improvement }\end{array}$} & $\begin{array}{c}\text { Environmental Education Research } \\
\text { https://doi.org/10.1080/13504622.2018.1455074 } \\
\end{array}$ & $25(4)$ \\
\hline \multicolumn{6}{|c|}{ CONTENIDO } \\
\hline Tipo y Diseño & $\begin{array}{l}\text { Población } \\
\text { y Muestra }\end{array}$ & Instrumentos & Aspectos éticos & Resultados & Conclusión \\
\hline $\begin{array}{l}\text { Tipo básica } \\
\text { exploratorio } \\
\text { Diseño no } \\
\text { experimental }\end{array}$ & $\begin{array}{c}20 \\
\text { profesores }\end{array}$ & Cuestionario & $\begin{array}{l}\text { Presentación de } \\
\text { información } \\
\text { objetiva }\end{array}$ & $\begin{array}{l}\text { En relación con los docentes de las escuelas ordinarias, los de las } \\
\text { escuelas de educación para el desarrollo sostenible perciben que } \\
\text { sus organizaciones escolares tienen una mayor calidad y } \\
\text { coherencia, con mayor potencial para apoyar la docencia y el } \\
\text { trabajo pedagógico en la práctica. }\end{array}$ & $\begin{array}{l}\text { Existe una variación } \\
\text { sustancial en las } \\
\text { percepciones de los } \\
\text { profesores de diferentes } \\
\text { escuelas de educación para } \\
\text { el desarrollo sostenible. La } \\
\text { solidez del modelo está } \\
\text { validada por la coherencia de } \\
\text { los resultados anteriores en } \\
\text { las mismas escuelas }\end{array}$ \\
\hline
\end{tabular}

Ciencia Latina Revista Científica Multidisciplinar, Ciudad de México, México.

ISN 2707-2207 / ISSN 2707-2215 (en línea), setiembre-octubre, 2021, Volumen 5, Número 5. https://doi.org/10.37811/cl rcm.v5i5.792 p.6744 


\begin{tabular}{|c|c|c|c|c|c|}
\hline \multicolumn{6}{|c|}{ DATOS } \\
\hline 13. Autor & Año & \multicolumn{2}{|c|}{ Nombre } & Revista & Vol. y núm. \\
\hline Green, Terrance & (2018) & \multicolumn{2}{|c|}{$\begin{array}{l}\text { School as Community, } \\
\text { Community as School: } \\
\text { Examining Principal } \\
\text { Leadership for Urban } \\
\text { School Reform and } \\
\text { Community Development }\end{array}$} & $\begin{array}{c}\text { Education and Urban Society } \\
\text { https://doi.org/10.1177\%2F0013124516683997 } \\
\end{array}$ & $50(2)$ \\
\hline \multicolumn{6}{|c|}{ CONTENIDO } \\
\hline Tipo y Diseño & $\begin{array}{c}\text { Población y } \\
\text { Muestra }\end{array}$ & Instrumentos & Aspectos éticos & Resultados & Conclusión \\
\hline $\begin{array}{c}\text { Tipo básica estudio } \\
\text { de caso } \\
\text { Diseño no } \\
\text { experimental }\end{array}$ & 1 director & $\begin{array}{l}\text { Entrevistas y } \\
\text { análisis } \\
\text { documental }\end{array}$ & $\begin{array}{l}\text { Presentación de } \\
\text { información } \\
\text { objetiva }\end{array}$ & $\begin{array}{l}\text { Las reformas de las escuelas urbanas que están } \\
\text { conectadas con los esfuerzos de desarrollo comunitario } \\
\text { equitativo son más sostenibles y que los directores juegan } \\
\text { un papel fundamental en la conducción de dichos } \\
\text { esfuerzos }\end{array}$ & $\begin{array}{l}\text { Las acciones del director para } \\
\text { apoyar la reforma escolar } \\
\text { urbana y el mejoramiento de la } \\
\text { comunidad incluyeron lo } \\
\text { siguiente: posicionó a la } \\
\text { escuela como un intermediario } \\
\text { social en la comunidad, } \\
\text { vinculó la cultura escolar a los } \\
\text { proyectos de revitalización de } \\
\text { la comunidad y conectó la } \\
\text { instrucción con las realidades } \\
\text { de la comunidad. }\end{array}$ \\
\hline
\end{tabular}

Ciencia Latina Revista Científica Multidisciplinar, Ciudad de México, México.

ISN 2707-2207 / ISSN 2707-2215 (en línea), setiembre-octubre, 2021, Volumen 5, Número 5. https://doi.org/10.37811/cl_rcm.v5i5.792 p.6745 


\begin{tabular}{|c|c|c|c|c|c|}
\hline \multicolumn{6}{|c|}{ DATOS } \\
\hline 14. Autor & Año & \multicolumn{2}{|c|}{ Nombre } & Revista & Vol. y núm. \\
\hline $\begin{array}{l}\text { Domínguez, Ana } \\
\text { Ruiz, Miguel } \\
\text { Huertas, Juan } \\
\text { Alonso, Jesús }\end{array}$ & (2019) & \multicolumn{2}{|c|}{$\begin{array}{l}17 \text { Development and } \\
\text { validation of the School } \\
\text { Climate Questionnaire for } \\
\text { Secondary and High School } \\
\text { Teachers (SCQ-SHST). }\end{array}$} & $\begin{array}{c}\text { Anales de Psicología } \\
\text { https://doi.org/10.6018/analesps.341001 } \\
\end{array}$ & $36(1)$ \\
\hline \multicolumn{6}{|c|}{ CONTENIDO } \\
\hline Tipo y Diseño & $\begin{array}{c}\text { Población y } \\
\text { Muestra }\end{array}$ & Instrumentos & Aspectos éticos & Resultados & Conclusión \\
\hline $\begin{array}{l}\text { Tipo básica } \\
\text { Diseño no } \\
\text { experimental }\end{array}$ & $\begin{array}{c}581 \\
\text { profesores } \\
\text { de } \\
\text { secundaria y } \\
\text { bachillerato. }\end{array}$ & cuestionario & $\begin{array}{l}\text { Presentación de } \\
\text { información } \\
\text { objetiva }\end{array}$ & $\begin{array}{l}\text { El diseño de los objetivos escolares termina siendo } \\
\text { una parte significativa del entorno escolar, } \\
\text { generosamente identificado con diferentes elementos } \\
\text { del entorno escolar como la naturaleza de la } \\
\text { iniciativa y las conexiones entre los instructores. }\end{array}$ & $\begin{array}{l}\text { Los resultados ofrecieron una } \\
\text { ayuda exacta para la utilización de } \\
\text { la encuesta propuesta entre las } \\
\text { escuelas, particularmente en } \\
\text { aquellas interesadas en articular } \\
\text { las intercesiones apuntadas hacia } \\
\text { un mayor desarrollo del clima de } \\
\text { aprendizaje a través de los siete } \\
\text { componentes del entorno escolar } \\
\text { a los que se tiende. }\end{array}$ \\
\hline
\end{tabular}

Ciencia Latina Revista Científica Multidisciplinar, Ciudad de México, México.

ISN 2707-2207 / ISSN 2707-2215 (en línea), setiembre-octubre, 2021, Volumen 5, Número 5. https://doi.org/10.37811/cl_rcm.v5i5.792 p.6746 


\begin{tabular}{|c|c|c|c|c|c|}
\hline \multicolumn{6}{|c|}{ DATOS } \\
\hline 15. Autor & Año & & mbre & Revista & Vol. y núm. \\
\hline $\begin{array}{l}\text { Cheng, Eric } \\
\mathrm{Wu}, \mathrm{S} \\
\mathrm{Hu}, \mathrm{Jim}\end{array}$ & (2017) & \multicolumn{2}{|c|}{$\begin{array}{l}18 \text { Knowledge management } \\
\text { implementation in the school } \\
\text { context: case studies on } \\
\text { knowledge leadership, } \\
\text { storytelling, and taxonomy }\end{array}$} & $\begin{array}{l}\begin{array}{c}\text { Educational Research for Policy and } \\
\text { Practice }\end{array} \\
\text { https://doi.org/10.1007/s10671-016-9200-0 }\end{array}$ & $16(2)$ \\
\hline \multicolumn{6}{|c|}{ CONTENIDO } \\
\hline Tipo y Diseño & $\begin{array}{l}\text { Población y } \\
\text { Muestra }\end{array}$ & Instrumentos & Aspectos éticos & Resultados & Conclusión \\
\hline $\begin{array}{l}\text { Tipo básica } \\
\text { exploratorio } \\
\text { Diseño no } \\
\text { experimental }\end{array}$ & $\begin{array}{l}30 \text { directores, } \\
\text { mandos } \\
\text { intermedios y } \\
\text { maestros. }\end{array}$ & Entrevistas & $\begin{array}{c}\text { Presentación de } \\
\text { información objetiva }\end{array}$ & $\begin{array}{l}\text { las estrategias centrales de la gestión del } \\
\text { conocimiento de personalización y } \\
\text { codificación pueden adoptarse para mejorar } \\
\text { el desarrollo escolar. }\end{array}$ & $\begin{array}{l}\text { El liderazgo del conocimiento, la } \\
\text { cultura de intercambio de } \\
\text { conocimientos y el apoyo al sistema de } \\
\text { gestión del conocimiento se } \\
\text { identificaron como factores de éxito } \\
\text { para que las escuelas implementen la } \\
\text { gestión del conocimiento. }\end{array}$ \\
\hline
\end{tabular}

Ciencia Latina Revista Científica Multidisciplinar, Ciudad de México, México.

ISN 2707-2207 / ISSN 2707-2215 (en línea), setiembre-octubre, 2021, Volumen 5, Número 5. https://doi.org/10.37811/cl_rcm.v5i5.792 p.6747 


\section{DATOS}

\begin{tabular}{|c|c|c|c|c|c|}
\hline 16. Autor & Año & \multicolumn{2}{|c|}{ Nombre } & Revista & Vol. y núm. \\
\hline $\begin{array}{l}\text { Lowe, Kevin } \\
\text { Harrison, Neil } \\
\text { Tennent, } \\
\text { Christine } \\
\text { Guenther, John } \\
\text { Vass, Greg } \\
\text { Moodie, Nikki }\end{array}$ & (2019) & \multicolumn{2}{|c|}{$\begin{array}{l}19 \text { Factors affecting the } \\
\text { development of school and } \\
\text { Indigenous community } \\
\text { engagement: A systematic } \\
\text { review }\end{array}$} & $\begin{array}{l}\text { The Australian Educational Researcher } \\
\text { https://doi.org/10.1007/s13384-019-00314-6 }\end{array}$ & $46(2)$ \\
\hline \multicolumn{6}{|c|}{ CONTENIDO } \\
\hline Tipo y Diseño & $\begin{array}{l}\text { Población } \\
\text { y Muestra }\end{array}$ & Instrumentos & Aspectos éticos & Resultados & Conclusión \\
\hline $\begin{array}{l}\text { Tipo básica } \\
\text { Diseño no } \\
\text { experimental }\end{array}$ & $\begin{array}{l}\quad 30 \\
\text { artículos. }\end{array}$ & $\begin{array}{c}\text { Análisis } \\
\text { documentario }\end{array}$ & $\begin{array}{l}\text { Presentación de } \\
\text { información } \\
\text { objetiva }\end{array}$ & $\begin{array}{l}\text { Los sistemas escolares y los aborígenes y los isleños del } \\
\text { Estrecho de Torres han reconocido desde hace mucho } \\
\text { tiempo los niveles de conflicto social, cultural y } \\
\text { epistémico que históricamente ha existido entre maestros } \\
\text { y escuelas, y estudiantes aborígenes, familias y } \\
\text { comunidades locales. }\end{array}$ & $\begin{array}{l}\text { Esta relación es a la vez } \\
\text { sintomática y causal del campo } \\
\text { más amplio y altamente complejo } \\
\text { de cuestiones y políticas que } \\
\text { sustentan las tensas historias que } \\
\text { existen entre muchas } \\
\text { comunidades y escuelas } \\
\text { aborígenes. }\end{array}$ \\
\hline
\end{tabular}

Ciencia Latina Revista Científica Multidisciplinar, Ciudad de México, México.

ISN 2707-2207 / ISSN 2707-2215 (en línea), setiembre-octubre, 2021, Volumen 5, Número 5. https://doi.org/10.37811/cl rcm.v5i5.792 p.6748 
3.3. Estudio sobre promoción de la salud y desarrollo escolar

\begin{tabular}{|c|c|c|c|c|c|c|}
\hline \multicolumn{7}{|c|}{ DATOS } \\
\hline 17. Autor & Año & & Nombre & Revista & & Vol. y núm. \\
\hline $\begin{array}{l}\text { Shinde, Sachin } \\
\text { Pereira, Bernadette } \\
\text { Khandeparkar, } \\
\text { Prachi } \\
\text { Sharma, Amit } \\
\text { Patton, George } \\
\text { Ross, David } \\
\text { Weiss, Helen } \\
\text { Patel, Vikram }\end{array}$ & (2017) & $\begin{array}{r}\text { The deve } \\
\text { multic } \\
\text { interve }\end{array}$ & $\begin{array}{l}\text { ment and pilot testing of a } \\
\text { onent health promotion } \\
\text { n (SEHER) for secondary } \\
\text { ols in Bihar, India }\end{array}$ & $\begin{array}{c}\text { Global Health Action } \\
\text { https://doi.org/10.1080/16549716.2017.1385 }\end{array}$ & 284 & $10(1)$ \\
\hline \multicolumn{7}{|c|}{ CONTENIDO } \\
\hline Tipo y Diseño & $\begin{array}{c}\text { Población y } \\
\text { Muestra }\end{array}$ & Instrumentos & Aspectos éticos & Resultados & & Conclusión \\
\hline $\begin{array}{l}\text { Tipo básica } \\
\text { Diseño no } \\
\text { experimental }\end{array}$ & 50 escuelas. & $\begin{array}{c}\text { Análisis } \\
\text { documentario }\end{array}$ & $\begin{array}{c}\text { Presentación de información } \\
\text { objetiva }\end{array}$ & $\begin{array}{l}\text { Las estrategias de intervención específicas } \\
\text { fueron entregadas en tres niveles (escuela } \\
\text { completa, grupo de estudiantes y consejería } \\
\text { individual) ya sea por un maestro } \\
\text { capacitado o un consejero no especializado }\end{array}$ & $\begin{array}{l}\text { Este } \\
\text { prop } \\
\text { pron } \\
\text { adol } \\
\text { secu } \\
\text { bajo } \\
\text { utiliz } \\
\text { aleat } \\
\text { evalt } \\
\text { renta }\end{array}$ & $\begin{array}{l}\text { enfoque SEHER } \\
\text { iona un marco para la } \\
\text { ión de la salud de los } \\
\text { entes en las escuelas } \\
\text { rias en entornos de } \\
\text { cursos. Ahora estamos } \\
\text { do un ensayo } \\
\text { zado por grupos para } \\
\text { su efectividad y } \\
\text { idad. }\end{array}$ \\
\hline
\end{tabular}

Ciencia Latina Revista Científica Multidisciplinar, Ciudad de México, México.

ISN 2707-2207 / ISSN 2707-2215 (en línea), setiembre-octubre, 2021, Volumen 5, Número 5. https://doi.org/10.37811/cl_rcm.v5i5.792 p.6749 


\begin{tabular}{|c|c|c|c|c|c|c|}
\hline \multicolumn{7}{|c|}{ DATOS } \\
\hline 18. Autor & Año & & & & Revista & Vol. y núm. \\
\hline $\begin{array}{l}\text { McIsaac, Jessie } \\
\text { Read, Kendra } \\
\text { Veugelers, Paul } \\
\text { Kirk, Sara }\end{array}$ & (2017) & 21 & $\begin{array}{r}\text { Culture matters } \\
\text { promo }\end{array}$ & $\begin{array}{l}\text { of school health } \\
\text { Canada }\end{array}$ & $\begin{array}{c}\text { Health Promotion International } \\
\frac{\text { https://doi.org/10.1093/heapro/dat0 }}{\underline{55}}\end{array}$ & $32(2)$ \\
\hline \multicolumn{7}{|c|}{ CONTENIDO } \\
\hline Tipo y Diseño & $\begin{array}{c}\text { Población y } \\
\text { Muestra }\end{array}$ & & Instrumentos & Aspectos éticos & Resultados & Conclusión \\
\hline $\begin{array}{l}\text { Tipo básica } \\
\text { Diseño no } \\
\text { experimental }\end{array}$ & $\begin{array}{l}23 \text { (directores, } \\
\text { maestros y } \\
\text { padres) } \\
9 \text { escuelas. }\end{array}$ & & Entrevistas & $\begin{array}{l}\text { Presentación de } \\
\text { información } \\
\text { objetiva }\end{array}$ & $\begin{array}{l}\text { Los resultados sugieren que, sin } \\
\text { abordar la cultura competitiva, que } \\
\text { se ve reforzada persistentemente por } \\
\text { estrictos mandatos académicos y } \\
\text { normas comunitarias poco } \\
\text { saludables, HPS será vulnerable a } \\
\text { circunstancias que impidan su } \\
\text { implementación. }\end{array}$ & $\begin{array}{l}\text { Considerando la importancia } \\
\text { emergente del bienestar mental, } \\
\text { También será importante } \\
\text { proporcionar a las escuelas la } \\
\text { capacidad y el apoyo del personal } \\
\text { adecuados y apropiados para } \\
\text { abordar este problema. Mantener } \\
\text { los efectos positivos de HPS } \\
\text { requerirá un compromiso y } \\
\text { colaboración continuos con } \\
\text { múltiples partes interesadas para } \\
\text { incorporar la promoción de la } \\
\text { salud en las normas de la } \\
\text { comunidad escolar. }\end{array}$ \\
\hline
\end{tabular}

Ciencia Latina Revista Científica Multidisciplinar, Ciudad de México, México.

ISN 2707-2207 / ISSN 2707-2215 (en línea), setiembre-octubre, 2021, Volumen 5, Número 5. https://doi.org/10.37811/cl_rcm.v5i5.792 p.6750 


\begin{tabular}{|c|c|c|c|c|c|}
\hline \multicolumn{6}{|c|}{ DATOS } \\
\hline 19. Autor & Año & \multicolumn{2}{|c|}{ Nombre } & Revista & Vol. y núm. \\
\hline $\begin{array}{l}\text { Fackler, Carol } \\
\text { Baugh, Nancy } \\
\text { Lovegren, Ann } \\
\text { Nemeroff, Carol } \\
\text { Whatley, Janet }\end{array}$ & (2021) & \multicolumn{2}{|c|}{ 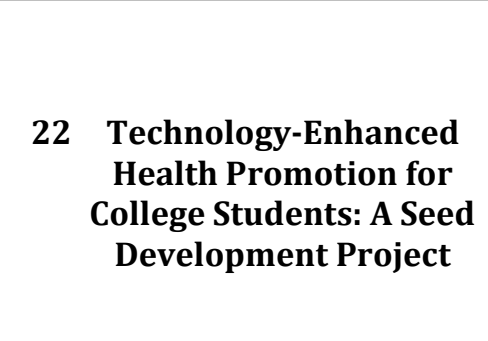 } & $\begin{array}{c}\text { Nursing Reports } \\
\text { https://doi.org/10.3390/nursrep11010014 }\end{array}$ & $11(1)$ \\
\hline \multicolumn{6}{|c|}{ CONTENIDO } \\
\hline Tipo y Diseño & $\begin{array}{c}\text { Población y } \\
\text { Muestra }\end{array}$ & Instrumentos & Aspectos éticos & Resultados & Conclusión \\
\hline $\begin{array}{c}\text { Tipo básica mixta } \\
\text { Diseño no } \\
\text { experimental }\end{array}$ & $\begin{array}{c}22 \\
\text { estudiantes. }\end{array}$ & Entrevistas & $\begin{array}{l}\text { Presentación de } \\
\text { información } \\
\text { objetiva }\end{array}$ & $\begin{array}{l}\text { Los participantes informaron una mayor conciencia de los } \\
\text { comportamientos alimentarios y sentimientos de } \\
\text { participación en el seguimiento de su consumo de frutas y } \\
\text { verduras. Los hallazgos sugieren que la tecnología se puede } \\
\text { utilizar para mejorar la efectividad y eficiencia de lograr las } \\
\text { metas individuales de las estudiantes relacionadas con una } \\
\text { vida saludable }\end{array}$ & $\begin{array}{l}\text { Se necesita más investigación } \\
\text { en el área de la gestión del estilo } \\
\text { de vida de salud asistida por } \\
\text { tecnología, incluida la } \\
\text { investigación cualitativa para } \\
\text { comprender más plenamente los } \\
\text { valores, las percepciones, las } \\
\text { necesidades y las preferencias } \\
\text { de los estudiantes universitarios } \\
\text { cuando se trata del uso de } \\
\text { tecnologías }\end{array}$ \\
\hline
\end{tabular}

Ciencia Latina Revista Científica Multidisciplinar, Ciudad de México, México.

ISN 2707-2207 / ISSN 2707-2215 (en línea), setiembre-octubre, 2021, Volumen 5, Número 5. https://doi.org/10.37811/cl_rcm.v5i5.792 p.6751 


\begin{tabular}{|c|c|c|c|c|c|}
\hline \multicolumn{6}{|c|}{ DATOS } \\
\hline 20. Autor & Año & \multicolumn{2}{|c|}{ Nombre } & Revista & Vol. y núm. \\
\hline $\begin{array}{l}\text { Horta, Rogério } \\
\text { Andersen, } \\
\text { Cristine } \\
\text { Pinto, Raquel } \\
\text { Horta, } \\
\text { Bernardo } \\
\text { Oliveira, } \\
\text { Maryane } \\
\text { Andreazzi, } \\
\text { Marco } \\
\text { Malta, Deborah }\end{array}$ & (2017) & \multicolumn{2}{|c|}{$23 \begin{array}{c}\text { Health promotion in school } \\
\text { environment in Brazil }\end{array}$} & $\begin{array}{c}\text { Revista de Saúde Pública } \\
\frac{\text { https://www.scielo.br/j/rsp/a/9wNcrJR3j }}{\underline{\text { RgGfKGGrxQGGSP/?lang=en }}}\end{array}$ & $51(0)$ \\
\hline \multicolumn{6}{|c|}{ CONTENIDO } \\
\hline Tipo y Diseño & $\begin{array}{l}\text { Población y } \\
\text { Muestra }\end{array}$ & Instrumentos & Aspectos éticos & Resultados & Conclusión \\
\hline $\begin{array}{l}\text { Tipo básica } \\
\text { transversal } \\
\text { Diseño no } \\
\text { experimental }\end{array}$ & $\begin{array}{l}27 \text { estratos } \\
\text { geográficos }\end{array}$ & cuestionario & $\begin{array}{l}\text { Presentación de } \\
\text { información } \\
\text { objetiva }\end{array}$ & $\begin{array}{l}\text { Los datos obtenidos indican que Brasil } \\
\text { todavía se preocupó muy mal por la } \\
\text { oferta alimentaria de los estudiantes en } \\
2012\end{array}$ & $\begin{array}{l}\text { Persistencia de las desigualdades en los indicadores } \\
\text { de promoción de la salud en las escuelas de Brasil, } \\
\text { destacando las diferencias entre las regiones del país } \\
\text { y entre escuelas públicas y privadas. Estas } \\
\text { desigualdades son más evidentes entre los indicadores } \\
\text { estructurales y muestran la necesidad de una mayor } \\
\text { inversión en indicadores de proceso para el país en su } \\
\text { conjunto. En este sentido, aparecen menos } \\
\text { desigualdades, pero las puntuaciones obtenidas } \\
\text { pueden considerarse bajas }\end{array}$ \\
\hline
\end{tabular}




\section{DISCUSIÓN}

Sobre la promoción de la salud, al respecto López, Canga, Mujika, Pardavila, Belintxon, Serrano y Pumar (2016) observan que el bienestar debe percibirse a partir de una medición agregada y no solo como un recurso individual. Garantiza que darse cuenta de esto es fundamental, ya que el deber al respecto sobrepasa al individuo y los entornos cotidianos donde los individuos crecen de manera directa influyen e incluso deciden sus formas de vida. En cualquier caso, los creadores expresan que la totalidad de lo anterior no parece haber tenido el reflejo que debería tener en la práctica. Desde una perspectiva, los planes de bienestar parecen ser planes de bienestar con destinos coordinados más en las mediaciones de las administraciones de bienestar que en los objetivos intersectoriales. Asimismo, si bien se han archivado diferentes encuentros con la utilización de aparatos, por ejemplo, la valoración de la influencia del bienestar, orientada a evaluar los impactos de enfoques, proyectos o tareas sobre la fortaleza de la población y su difusión en dicha población, estos en general serán cero. en unidades cercanas que realmente no sugieren los arreglos o actividades que más afectan la solidez de la población. En un sentido similar, Jane, Hagger, Foster, Ho y Pal (2018) hicieron referencia a que el bienestar debe ser tratado desde un punto de vista social, y para ello deben existir técnicas que funcionen con precisión como ayuda amigable. De esta manera, los creadores expresaron que la ayuda social es cada uno de los activos sociales que los individuos ven accesibles o realmente brindados por no expertos en lo que respecta a los grupos de atención formal y las conexiones de ayuda casual. Incorpora la disposición de activos materiales, datos útiles y consideración entusiasta, con correspondencias relacionales.

Desde otro contexto, Cislaghi y Heise (2018) en una perspectiva normativa social para la promoción de la salud en países de bajos recursos económicos menciona que las normas sociales pueden influir en gran medida en las elecciones y los comportamientos relacionados a la salud de las personas. Desde tiempo atrás, académicos y profesionales han intentado cada vez más aprovechar la influencia de las normas sociales para mejorar la salud de las personas a nivel mundial, ante ello, se han encontrado que los países de bajos ingresos no cuenta con un sistema de comprensión de estas normas. Esta brecha ha llevado a intervenciones sin éxitos que se enfocan exclusivamente en las normas sociales sin una conciencia más amplia de cómo otros factores institucionales, materiales, individuales y sociales afectan la práctica nociva. Para los autores, enfatizar las normas 
excluyendo a otros factores podría en última instancia, desacreditar las estrategias las normas sociales, no porque sean defectuosas, sino, porque por sí solos no son capaces de modificar comportamientos. Al respecto Lavarack (2017) en desafío de cambio de comportamiento y promoción de la salud, manifestó que la evidencia sobre la efectividad de los enfoques de cambio de comportamiento - qué funciona y qué no funciona - no es clara. Lo que sí sabemos es que las intervenciones individuales que se dirigen a un riesgo conductual específico tienen poco impacto en los determinantes que realmente causan mala salud, especialmente para las personas vulnerables. Manifiesta también que el futuro del cambio de comportamiento y la promoción de la salud pasa por la aplicación de una estrategia integral con tres componentes centrales: (1) un enfoque de cambio de comportamiento; (2) un marco de políticas sólido que crea un entorno de apoyo y (3) el empoderamiento de las personas para obtener más control sobre la toma de decisiones sobre estilos de vida saludables.

Sobre el desarrollo escolar, Arhipova, Kokina y Michaelsson (2018) en competencias de gestión del director de la escuela para un desarrollo escolar existo, los autores manifestaron que la solución de los problemas de gestión de la educación se ve muy afectada por las ideas del enfoque de sistema que tratan las acciones como un sistema unificado que consta de elementos relacionados entre sí con la interacción constante de factores ambientales internos y externos. Asimismo, indicaron que la naturaleza cambiante del entorno escolar ha impuesto nuevas demandas a los líderes educativos, en donde, el conocimiento de la gestión escolar, las finanzas, los asuntos legales y los mandatos estatales que alguna vez fue el enfoque principal para la preparación de los líderes escolares, ahora, la reforma educativa ha creado una necesidad urgente de un fuerte énfasis en el desarrollo de habilidades de liderazgo instructivo para promover una buena enseñanza y un aprendizaje de alto nivel. Al respecto, Hirsh y Segolsson (2017) en habilitar el desarrollo escolar y el aprendizaje colaborativo, mencionaron que, la manera en que la escuela organiza el trabajo de desarrollo escolar impulsado por los maestros, al transformar las reglas, la división del trabajo y los artefactos mediadores del sistema de actividades, permite el aprendizaje colaborativo y el análisis de instrucción que involucraron a todos los maestros de la escuela. Es por eso que Snoek, Bekebrede, Hanna, Creton y Edzes (2017) en contribución al desarrollo escolar, mencionaron que, cuando la enseñanza se considera una actividad colaborativa, el objetivo de los proyectos de 
investigación en las escuelas debe superar los niveles individuales y personales y tener como objetivo contribuir a la reflexión informada por la investigación de un equipo de profesores. Sin embargo, Mogren, Gericke y Scherp (2018) quienes aplicaron un modelo de organización para mejorar el enfoque escolar mediante el desarrollo sostenible. Los autores mencionan que, en relación con los docentes de las escuelas ordinarias, los de las escuelas de enfoque de educación para el desarrollo sostenible perciben que sus organizaciones escolares tienen una mayor calidad y coherencia, con mayor potencial para apoyar la docencia y el trabajo pedagógico en la práctica.

Sobre, la promoción de la salud y el desarrollo escolar, finalmente, de acuerdo a los resultados presentados, se entiende que la promoción de la salud es un eje central para el desarrollo de un país. Es por eso que la educación tiene un papel trascendental en el cumplimiento de la misma. Tal como lo mencionan Green (2016) que desde hace décadas las escuelas están conectadas mediante un esfuerzo al desarrollo comunitario y son las autoridades quienes tienen la responsabilidad y el compromiso de que estos sean así. De esta manera, el rol que tienen las autoridades educativas condiciona el desarrollo social. En ese sentido Cheng, Wu y Hu (2017) en implementación de la gestión del conocimiento en el contexto escolar, manifiesta que los sistemas de gestión, que ahorran tiempo y transfieren ideas, experiencias y conocimientos de manera más eficiente, podrían ayudar a las escuelas a cumplir los objetivos de salud y aliviar el estrés ocupacional que inevitablemente acompaña al cambio y al progreso.

\section{CONCLUSIONES}

En relación a la promoción de la salud, de acuerdo a las investigaciones realizadas, se concluye que, la promoción de la salud es una interacción mundial que permite a las personas expandir la autoridad sobre su bienestar para desarrollarlo aún más, enfocándose en el fortalecimiento de las personas, pero además que considera los círculos políticos, sociales, monetarios y naturales que impactan el bienestar y la salud. En ese sentido, la promoción de la salud es participativa, intersectorial y basado en la población por lo que su campo de aplicación se da en diferentes niveles. Asimismo, involucra un enfoque multidisciplinario, integrando un sistema completo para mejorar la salud y el bienestar. Por otro lado, las normas sociales influyen en gran medida en las decisiones y los comportamientos relacionados con la salud de las personas, sin embargo, existe un 
problema en cuanto a la aplicación de estas normas por países de ingresos bajos, quienes carecen de un marco para comprender cómo estas interactúan en beneficio de la salud.

En cuanto al desarrollo escolar, se concluye que, este es importante para el crecimiento de la sociedad, debido a que la educación es un factor clave para lograr el éxito en el cumplimiento de los objetivos propuestos en relación a la salud. Cuando todos los actores educativos están comprometidos en la promoción de la salud, existe más probabilidades de que la calidad de vida de las personas mejore, puesto que cambian de comportamiento y actitudes. En ese sentido, las escuelas son un entorno apropiado para la promoción de la salud y el bienestar emocional de las personas, logrando un resultado importante en la calidad de vida de estas.

En base a las conclusiones, a modo de recomendación, el gobierno nacional, así como también, el regional y el local, deben proporcionar a las escuelas la capacidad y el apoyo necesario para que estas logren cumplir su propósito; el de generar actitudes y comportamientos positivos en la población.

Además, es necesario que en los centros educativos se implementen programas, talleres, congresos, conferencias, etc., promocionando la importancia de una vida saludable. Asimismo, es importante que los recursos sociales, como son la participación de la familia, la pareja y los compañeros, en forma de información, ayuda material y estímulo son útiles y funcionan como estrategia para mejorar la salud.

Finalmente, es importante abordar los principales desafíos de la salud pública, cambiando los enfoques tradicionales de la educación para la salud centrado en riesgos de salud persona y elecciones de estilo de vida, y pasar a poner la atención en las políticas e intervenciones ambientales integrales. En ese sentido, el acceso equitativo a la educación sobre salud de calidad y aprendizaje permanente deben ser elementos claves en la promoción moderna de la salud.

\section{REFERENCIAS BIBLIOGRAFICAS}

Albahri, A. S., Alwan, J. K., Taha, Z. K., Ismail, S. F., Hamid, R. A., Zaidan, A. A., Albahri, O. S., Zaidan, B. B., Alamoodi, A. H., \& Alsalem, M. A. (2021). IoTbased telemedicine for disease prevention and health promotion: State-of-the-Art.

Journal of Network and Computer Applications, 173, 102873. https://doi.org/10.1016/j.jnca.2020.102873

Arhipova, O., Kokina, I., \& Michaelsson, A. R. (2021). SCHOOL PRINCIPAL'S 


\section{MANAGEMENT COMPETENCES FOR SUCCESSFUL SCHOOL} DEVELOPMENT. Tiltai, 79(1), 63-76. https://doi.org/10.15181/tbb.v78i1.1757

Arias Ortiz, E., Rieble Aubourg, S., Álvarez Marinelli, H., Rivera, M. C., Viteri, A., López, Á., Pérez Alfaro, M., Vásquez, M., Bergamaschi, A., Noli, A., Ortiz Guerrero, M., \& Scannone, R. (2020). La educación en tiempos del coronavirus: Los sistemas educativos de América Latina y el Caribe ante COVID-19. Banco Interamericano de

Desarrollo. https://doi.org/http://dx.doi.org/10.18235/0002337

Cajina Pérez, L. N. (2020). Importancia de la Educación para la Salud en currículo educativo. Revista Electrónica de Conocimientos, Saberes y Prácticas, 3(1). https://doi.org/https://doi.org/10.5377/recsp.v3i1.9799

Cheng, E. C. K., Wu, S. W., \& Hu, J. (2017). Knowledge management implementation in the school context: case studies on knowledge leadership, storytelling, and taxonomy. Educational Research for Policy and Practice, 16(2), 177-188. https://doi.org/10.1007/s10671-016-9200-0

Cislaghi, B., \& Heise, L. (2019). Using social norms theory for health promotion in lowincome countries. Health Promotion International, 34(3), 616-623. https://doi.org/10.1093/heapro/day017

Domínguez, A. Q., Ruiz, M. Á., Huertas, J. A., \& Alonso-Tapia, J. (2019). Development and validation of the School Climate Questionnaire for Secondary and High School Teachers (SCQ-SHST). Anales de Psicología, 36(1), 155-165. https://doi.org/10.6018/analesps.341001

Fackler, C. A., Baugh, N., Lovegren, A. A., Nemeroff, C., \& Whatley Blum, J. (2021). Technology-Enhanced Health Promotion for College Students: A Seed Development Project. Nursing Reports, 11(1), 143-151. https://doi.org/10.3390/nursrep11010014

Green, T. L. (2018). School as Community, Community as School: Examining Principal Leadership for Urban School Reform and Community Development. Education and Urban Society, 50(2), 111-135. https://doi.org/10.1177/0013124516683997

Hernández, R., Fernández, C., \& Baptista, P. (2014). Metodología de la investigación (Sexta ed., Issue 9). McGraw-Hill / Interamericana Editores, S.A. de C.V. https://doi.org/10.1017/CBO9781107415324.004 
Hirsh, A., \& Segolsson, M. (2019). Enabling teacher-driven school-development and collaborative learning: An activity theory-based study of leadership as an overarching practice. Educational Management Administration \& Leadership, 47(3), 400-420. https://doi.org/10.1177/1741143217739363

Horta, R. L., Andersen, C. S., Pinto, R. O., Horta, B. L., Oliveira-Campos, M., Andreazzi, M. A. R. de, \& Malta, D. C. (2017). Health promotion in school environment in Brazil. Revista de Saúde Pública, 51. https://doi.org/10.1590/s15188787.2017051006709

Jane, M., Hagger, M., Foster, J., Ho, S., \& Pal, S. (2018). Social media for health promotion and weight management: a critical debate. BMC Public Health, 18(1), 932. https://doi.org/10.1186/s12889-018-5837-3

Laverack, G. (2017). The Challenge of Behaviour Change and Health Promotion. Challenges, 8(2), 25. https://doi.org/10.3390/challe8020025

López, O., Canga, N., Mujika, A., Pardavila, M., Belintxon, M., Serrano, I., \& Pumar, M. (2017). Cinco paradojas de la promoción de la salud. Gaceta Sanitaria, 31(3), 269-272. https://doi.org/10.1016/j.gaceta.2016.10.011

Lowe, K., Harrison, N., Tennent, C., Guenther, J., Vass, G., \& Moodie, N. (2019). Factors affecting the development of school and Indigenous community engagement: A systematic review. The Australian Educational Researcher, 46(2), 253-271. https://doi.org/10.1007/s13384-019-00314-6

McIsaac, J.-L. D., Read, K., Veugelers, P. J., \& Kirk, S. F. L. (2017). Culture matters: a case of school health promotion in Canada. Health Promotion International, 32(2), 207-217. https://doi.org/10.1093/heapro/dat055

Ministerio de la Salud. (2017). Lineamientos de política de promoción de la salud en el Perú. Ministerio de la Salud. http://bvs.minsa.gob.pe/local/MINSA/4142.pdf

Mogren, A., Gericke, N., \& Scherp, H.-Å. (2019). Whole school approaches to education for sustainable development: a model that links to school improvement. Environmental Education Research, 25(4), 508-531. https://doi.org/10.1080/13504622.2018.1455074

Nutbeam, D. (2019). Health education and health promotion revisited. Health Education Journal, 78(6), 705-709. https://doi.org/10.1177/0017896918770215

O’Connor, C., Dyson, J., Cowdell, F., \& Watson, R. (2018). Do universal school-based 
mental health promotion programmes improve the mental health and emotional wellbeing of young people? A literature review. Journal of Clinical Nursing, 27(3-4). https://doi.org/10.1111/jocn.14078

Organización de las Naciones Unidas para la Educación la Ciencia y la Cultura. (2020).

La educación en tiempos de la pandemia de COVID-19. CEPAL, UNESCO. https://www.cepal.org/fr/node/51998

Organización Mundial de la Salud. (2016). ¿Qué es la promoción de la salud? Who.Int. https://www.who.int/features/qa/health-promotion/es/

Organización Panamericana de la Salud. (2020). Promoción de la Salud. Paho.Org. https://www.paho.org/es/temas/promocion-salud

Reátegui Del Castillo, E. L. (2008). Saber sobre promoción de la salud en familias y personal de salud [Universidad Nacional de Trujillo]. https://dspace.unitru.edu.pe/handle/UNITRU/5411

Sarria Santamera, A., \& Del Villar Alvarez, F. (2014). Promoción de la salud en la comunidad (Universidad Nacional de Educación a Distancia - UNED (ed.)). https://dialnet.unirioja.es/servlet/libro?codigo=565425

Shinde, S., Pereira, B., Khandeparkar, P., Sharma, A., Patton, G., Ross, D. A., Weiss, H. A., \& Patel, V. (2017). The development and pilot testing of a multicomponent health promotion intervention (SEHER) for secondary schools in Bihar, India. Global Health Action, $10(1), \quad 1385284$. https://doi.org/10.1080/16549716.2017.1385284

Snoek, M., Bekebrede, J., Hanna, F., Creton, T., \& Edzes, H. (2017). The contribution of graduation research to school development: graduation research as a boundary practice. European Journal of Teacher Education, 40(3), 361-378. https://doi.org/10.1080/02619768.2017.1315400

Verra, S. E., Benzerga, A., Jiao, B., \& Ruggeri, K. (2019). Health Promotion at Work: A Comparison of Policy and Practice Across Europe. Safety and Health at Work, 10(1), 21-29. https://doi.org/10.1016/j.shaw.2018.07.003 